\title{
A CONVENIENT METHOD FOR THE DETERMINATION OF THE APPROXIMATE CARDIAC OUTPUT IN MAN
}

\author{
By JOHN S. DONAL, JR. \\ (From the Laboratory of Pharmacology of the University of Pennsylvania, Philadelphia)
}

(Received for publication June 29, 1937)

Although the ethyl iodide method of Starr and Gamble (1) and the acetylene method of Grollman (2) give useful results in the determination of the cardiac output in man, they require special apparatus and a time consuming technique not easy to master. It appeared that if the determination of the cardiac output is to become a practical procedure for the clinic a further simplification of methods is necessary, and with this end in view the possibilities of using oxygen and carbon dioxide for this purpose were reinvestigated. The plan was to devise the simplest possible procedure, to make the necessary assumptions, and then to compare the results with the values secured by means of ethyl iodide and acetylene.

A method has been developed ${ }^{1}$ by which the cardiac output may be estimated from a determination of metabolism and the analysis of the oxygen and carbon dioxide contents of only two samples, collected during a single rebreathing procedure much like that used in Grollman's acetylene method. The results obtained by this new oxygen method have been found to be in reasonably good agreement with those secured by the use of ethyl iodide and acetylene.

\section{METHOD}

If assumptions to be discussed hold, the cardiac output can be determined from the solution of two simultaneous equations of the Fick type, certain items of each having been obtained under somewhat different conditions.

For the first equation the normal condition is taken. We have:

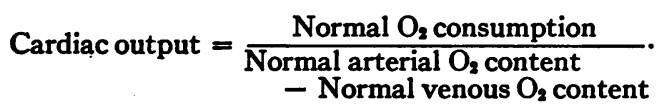

For the determination of the corresponding values of the second equation the subject re-

1 The work was carried out in the Laboratory of Research Therapeutics in the Hospital of the University of Pennsylvania. breathes, for a brief period, a mixture low in oxygen; and again we have:

Cardiac output

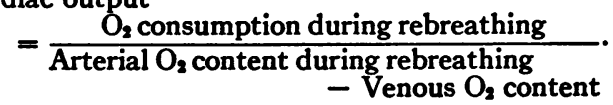

On the assumption that the cardiac output and the oxygen content of the venous blood have the same values in the two experiments, the two equations $(1, a)$ and $(1, b)$ may be combined mathematically so as to eliminate the unknown venous oxygen content. The cardiac output is given by the resulting equation:

$$
\begin{aligned}
& \text { Cardiac output } \\
& \text { Normal } \mathrm{O}_{2} \text { consumption } \\
& =\frac{-\mathrm{O}_{2} \text { consumption during the rebreathing. }}{\text { Normal arterial } \mathrm{O}_{2} \text { content }} \text { - Arterial } \mathrm{O}_{2} \text { content during the rebreathing }
\end{aligned}
$$

\section{APPARATUS}

The apparatus necessary for rebreathing is similar to that employed by Grollman for rebreathing acetylene, except that two three-way valves and two rubber bags are employed, making it almost identical with the apparatus of Gladstone (3).

One needs (1) a mouthpiece connected by (2) a short connecting tube of $3 \mathrm{~cm}$. diameter with side tubes of $4 \mathrm{~mm}$. bore for sampling, leading to (3) the valves, permitting connection of the subject with room air, or with (4) a 4 liter rubber bag, or with (5) a small spirometer or another 4 liter rubber bag. In addition, one needs (6) two Haldane sampling tubes, the upper stopcocks bored to not less than $4 \mathrm{~mm}$. ; with mercury, rubber tubing and a reservoir to permit the production of a Toricellian vacuum; (7) a Haldane gas analyzer or one of its modifications, (8) a stop watch, (9) a metronome, (10) rubber connecting tubing, (11) a nose clip and (12) a supply of nitrogen. Finally (13), any standard method for the estimation of metabolic rate may be employed. We use the Benedict-Roth (21), employing the spirometer for the additional purpose mentioned above. 
It has been found advantageous, although not necessary, to enclose the rebreathing bag in an air-tight metal container having an outlet connected to the Benedict-Roth spirometer, so that a graphic record of changes in the bag volume during filling and rebreathing may be obtained by displacement of air outside the bag.

\section{PROCEDURE}

Two rebreathing techniques have been employed, the simpler (1), identical with that of Grollman, being used only when the vital capacity is normal. The second (2), much like that of Gladstone (3), is used under other circumstances.

(1) Only one rebreathing bag is employed, filled initially with about $2500 \mathrm{cc}$. of nitrogen. The metronome is started at from 24 to 30 beats a minute. The subject, at first quietly breathing room air through the mouthpiece, is instructed to make a maximal expiration at command and then to inhale and exhale maximally, keeping time with the metronome. The operator connects the subject with the bag after the first maximal expiration, assures himself that time is being kept and the bag emptied at each inspiration, and collects samples from the last portions of the 6th and 10th expirations, noting the time between collections with the stop watch.

(2) In some patients with low vital capacity the first procedure may yield a lung-bag mixture too high in oxygen. Therefore the following technique was employed.

A preliminary estimation of the approximate vital capacity is made by having the subject inhale various amounts of air from the bag or spirometer after a maximal expiration.

A measured quantity of nitrogen, a little less than the patient could inhale, is placed in bag $A$; a larger, unmeasured amount in bag $B$ or in the spirometer.

The rebreathing technique is identical with (1) except that after the first maximal expiration to room air the subject is connected with bag $B$, or the spirometer, for a full respiratory cycle, and then connected with bag $A$ for the remainder of the rebreathing. Timed samples are taken from the last portions of the 5th and 9th expirations into bag $A$. The samples are analyzed for oxygen and carbon dioxide in the usual manner.

The metabolic rate is estimated either before or after the rebreathing.

\section{CALCULATION OF RESULTS}

This can be illustrated best by employing data obtained from a typical experiment. All volumes given are for dry gas under standard conditions. We have:

1. Normal oxygen consumption $=260 \mathrm{cc}$. per minute.

2. Normal arterial oxygen content. The oxygen capacity of the blood may be assumed to be $200 \mathrm{cc}$. per liter if the subject is normal, or may be estimated from the hemoglobin concentration. The arterial blood is as- sumed to be 96 per cent saturated. In this instance normal arterial oxygen content is $192 \mathrm{cc}$. per liter.

3. Oxygen consumption during the rebreathing.

Nitrogen in rebreathing bag initially $=2310 \mathrm{cc}$.

Assumed residual air $=1125 \mathrm{cc}^{2}$

Total initial lung-bag volume $\quad=3435 \mathrm{cc}$.

The average lung-bag volume during the rebreathing is assumed equal to the initial lung-bag volume.

Time between collection of samples $=9.8$ seconds.

\begin{tabular}{|c|c|c|c|}
\hline By analysis & $\begin{array}{l}\mathrm{CO}_{2} \\
\text { per } \\
\text { cent }\end{array}$ & $\begin{array}{c}\mathrm{O}_{2} \\
\text { per } \\
\text { cent }\end{array}$ & $\begin{array}{c}\mathrm{N}_{2} \\
\text { per } \\
\text { cent }\end{array}$ \\
\hline $\begin{array}{l}\text { First sample } \ldots \ldots \ldots \ldots \ldots \\
\text { Second sample } \ldots \ldots \ldots \ldots \ldots \\
\text { Average percentage } \ldots \ldots \ldots \ldots \\
\text { Average tension (saturated at } \\
\left.\quad 37^{\circ} \mathrm{C} \text {., barometer } 766\right) \ldots \ldots\end{array}$ & $\begin{array}{c}4.98 \\
5.57 \\
5.26 \\
37.9 \mathrm{~mm}\end{array}$ & \begin{tabular}{|l|}
5.14 \\
5.04 \\
5.09 \\
$36.5 \mathrm{~mm}$
\end{tabular} & $\begin{array}{l}89.88 \\
89.39\end{array}$ \\
\hline
\end{tabular}

Oxygen consumption during the rebreathing

$=$ (lung-bag volume) $\times$ (change of oxygen percentage in the lung-bag system)

$\times\left(\frac{60}{\text { seconds between collection of samples }}\right)$

$=(3435)(0.10)\left(\frac{60}{9.8}\right)$

$=21$ cc. per minute, dry under standard conditions.

4. Arterial oxygen content during the rebreathing. The nomogram of Henderson, et al. (5) is consulted. The percentage oxygen saturation is determined from the average oxygen and carbon dioxide tensions of the two samples. In this instance it is $\mathbf{7 2 . 5}$ per cent. Hence:

Arterial oxygen content $=72.5 \times 200=145 \mathrm{cc}$. per liter.

5. Calculation of cardiac output. Substituting the preceding four values in Equation 2:

$$
\text { Cardiac output }=\frac{260-21}{192-145}=5.1 \text { liters per minute. }
$$

\section{MAGNITUDE OF ERRORS INHERENT IN ASSUMP-} TIONS AND TECHNIQUE

Influence of increases in the cardiac output during the rebreathing, and of errors in the assumed value of residual air

In combining the expressions evaluated by the two determinations of oxygen consumption as two simultaneous equations (Equations $1 a, b$ and 2 under " method"), the equality of the cardiac outputs under the two conditions has been assumed.

This assumption introduces an error into the results because the acceleration of the circulation known to result from rebreathing will give an oxygen consumption which is erroneously high.

${ }^{2}$ From the work of Hurtado et al. (4), their average value being $1360 \mathrm{cc}$., saturated at $37^{\circ} \mathrm{C}$. 
Fortunately, however, the low oxygen tension during the rebreathing makes the corresponding oxygen consumption, the second term in the numerator of Equation 2, very small. Large percentage errors in this term, therefore, can have but little effect upon the calculated cardiac output. For the same reason, an error in the volume of the residual air, assumed for the calculation of this oxygen consumption during rebreathing, will produce a negligible effect upon the results.

That these errors are small may perhaps be understood more easily from a consideration of Figure 1. For a representative subject the oxy-

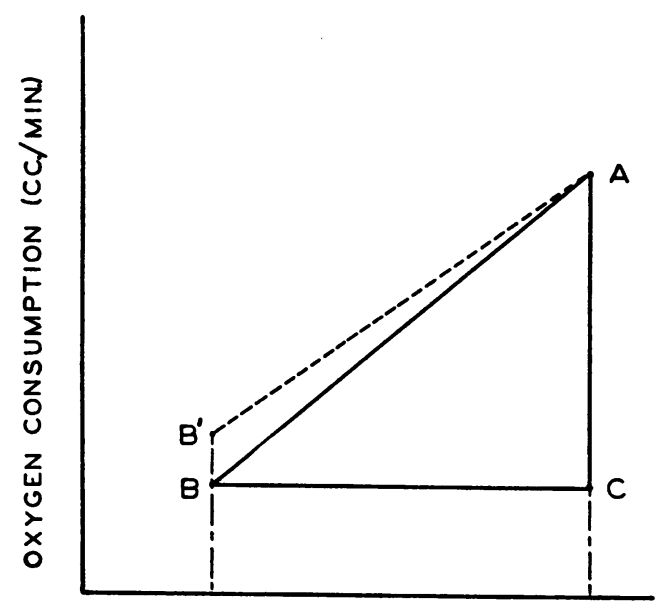

ARTERIAL OXYGEN CONTENT (CC/LITER)

Fig. 1. The Error Resulting from an Alteration in Cardiac Output during the Rebreathing

The cardiac output may be represented by the slope of the line $A B$ (see text). An increase of the cardiac output during the rebreathing decreases the calculated result to the value of the slope of the line $A B^{\prime}$. The error is small, however, if the oxygen tension in the lungs during the rebreathing is not far from the oxygen tension of the mixed venous blood, a condition which may conveniently be attained experimentally.

gen consumption of Equation 1 $a$, is plotted at point $A$ as a function of the assumed arterial oxygen content of $192 \mathrm{cc}$. per liter. The quantities of Equation $1 b$, i.e., the oxygen consumption measured during a rebreathing experiment and its corresponding arterial oxygen content, are plotted as point $B$. If the line $B C$ is drawn parallel to the axis of abscissae it will be seen that the line $(A-C)$ represents the numerator of the right hand side of Equation (2) and the line $(C-B)$ its denominator. Therefore, from Equation 2,
$(A-C) /(C-B)$, or the slope of the line $A B$, represents the cardiac output.

It is obvious that this error in the cardiac output, for any given percentage error $\left(B^{\prime}-B\right)$ in the oxygen consumption during the rebreathing, becomes less as the rebreathing is performed at an oxygen tension nearer equilibrium with the mixed venous blood, for as the absolute value of the ordinate at $B$ (the oxygen consumption) decreases, the difference $\left(B^{\prime}-B\right)$ must decrease and the slope of the line $A B^{\prime}$ (measured cardiac output) approaches the slope of $A B$ (true cardiac output).

Since the mixture rebreathed consists initially of nitrogen alone, the oxygen tension in the lungs is never such as to make the oxygen consumption during the rebreathing experiment more than a small fraction of the consumption measured at the normal alveolar oxygen levels. Thus, with the normal subjects studied by the first rebreathing technique (noted above under "Procedure") the average oxygen consumption during the experiments was 9.5 per cent of the average basal oxygen consumption of these subjects. Similarly, for the clinical subjects studied by the second rebreathing technique the corresponding value was 14 per cent.

To study the errors resulting, in actual practice, from the increase of cardiac output during the rebreathing, additional experiments were performed upon the first 9 of the normal subjects of Table $I$, in each case on the same day and after an additional 20 minute rest period. After a maximal expiration to the room the subject rebreathed a measured volume of a mixture of about 50 per cent oxygen in nitrogen. The residual air volumes were then determined from samples of the last portions of the initial maximal expirations to the room and of the first inspirations from the bag. Knowing the residual airs, timed samples of the 6th, and 10th or 11th expirations to the bag permitted the determination of the oxygen consumptions during the rebreathing. The results are compared with the basal oxygen consumptions in Table II, and the average increase of oxygen consumption during the rebreathing, which has been assumed to be the average increase of corresponding cardiac output, was found to be 66 per cent. Recomputation of the values of cardiac output for the 9 subjects, correcting the 
oxygen consumptions for the average increase of 66 per cent during the rebreathings, has shown that the results by our oxygen method must have been about 6 per cent too low.

TABLE I

Values of cardiac output

\begin{tabular}{|c|c|c|c|c|}
\hline Subject & $\begin{array}{l}\text { Ethyl iodide } \\
\text { method }\end{array}$ & $\begin{array}{c}\text { Acetylene } \\
\text { method }\end{array}$ & & $\begin{array}{l}\text { Oxygen } \\
\text { method }\end{array}$ \\
\hline & $\begin{array}{l}\text { liters per } \\
\text { minute }\end{array}$ & $\begin{array}{l}\text { liters per } \\
\text { minute }\end{array}$ & & $\begin{array}{l}\text { liters per } \\
\text { minute }\end{array}$ \\
\hline \multicolumn{5}{|c|}{ NORMAL SUBJECTS } \\
\hline $\begin{array}{c}1 \\
2 \\
3 \\
4 \\
5 \\
6 \\
7 \\
8 \\
9 \\
10 \\
11 \\
\text { Averages: }\end{array}$ & $\begin{array}{c}2.6,3.0 \\
4.3,3.3 \\
5.2,4.6 \\
3.8,4.2 \\
3.6,3.5 \\
6.9,7.9 \\
4.1,3.8 \\
4.8,4.9 \\
3.2,2.6 \\
4.0,4.2 \\
4.4 \\
4.23\end{array}$ & $\begin{array}{l}3.7 \\
4.0 \\
4.7 \\
5.7 \\
3.6 \\
7.1 \\
3.8 \\
4.0 \\
3.2 \\
3.6 \\
4.0 \\
4.30\end{array}$ & & $\begin{array}{c}3.8 \\
3.6 \\
3.2 \\
3.5 \\
3.2 \\
5.3 \\
4.4 \\
5.9 \\
2.6 \\
4.2,4.1 \\
4.5 \\
4.00\end{array}$ \\
\hline \multicolumn{5}{|c|}{ CLINICAL SUBJECTS } \\
\hline Subject & $\begin{array}{c}\text { Ethyl } \\
\text { iodide } \\
\text { method }\end{array}$ & $\begin{array}{l}\text { Oxygen } \\
\text { method }\end{array}$ & $\begin{array}{l}\text { Hemo- } \\
\text { globin }\end{array}$ & $\begin{array}{c}\text { Basal } \\
\text { oxysen } \\
\text { consump- } \\
\text { tion }\end{array}$ \\
\hline $\begin{array}{c}12 \\
13 \\
14 \\
15 \\
16 \\
17 \\
18 \\
\text { Averages: }\end{array}$ & $\begin{array}{c}\text { liters per } \\
\text { minute } \\
2.6,3.0 \\
6.0,5.9 \\
5.3,6.3 \\
3.5,2.8 \\
5.1 \\
3.0,4.1 \\
4.4 \\
4.39\end{array}$ & $\begin{array}{c}\text { liters per } \\
\text { minute } \\
2.8,3.0 \\
6.2,6.6 \\
7.4 \\
3.0,2.7 \\
5.3,4.8 \\
3.0,2.6 \\
3.9 \\
4.47\end{array}$ & $\begin{array}{r}\text { per } \\
\text { cent } \\
76 \\
52 \\
46 \\
100 \\
100 \\
95 \\
100\end{array}$ & $\begin{array}{c}\text { cc. per } \\
\text { minsule } \\
169 \\
279 \\
257 \\
169 \\
241 \\
176 \\
266\end{array}$ \\
\hline
\end{tabular}

TABLE II

Additional data on nine of the subjects of Table I

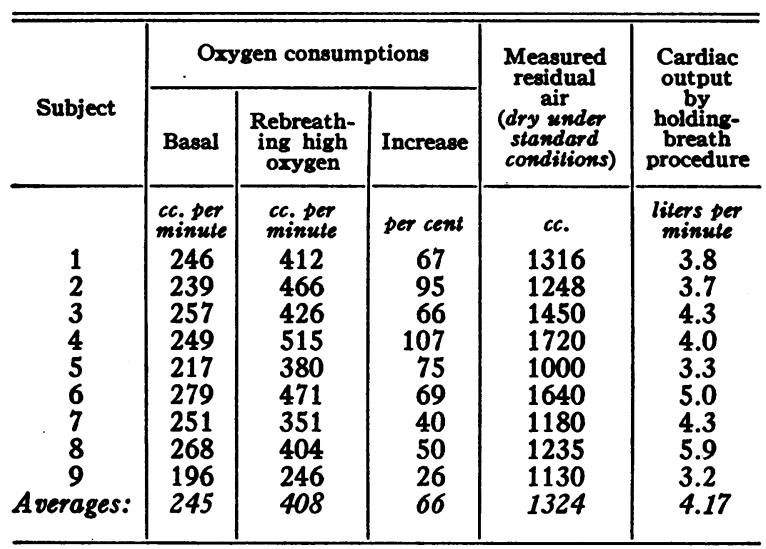

It will be seen from Table II that the measured values of residual air of the first 9 normal subjects averaged 18 per cent higher than the assumed value of $1125 \mathrm{cc}$. used in computing the results of Table I. However, when the results for these subjects were recalculated, using the measured residual airs, the average reduction in the values of cardiac output was less than 1 per cent.

In order to determine the effect of a reduction in the respiratory gymnastics incident to the method, additional experiments at low oxygen tensions were performed upon the above 9 basal subjects. The procedure of holding the breath according to Krogh and Lindhard (6) was employed, together with a modification of the mixing technique of Gladstone (3). The subject expired maximally to air at zero time, emptied a bag containing about $3600 \mathrm{cc}$. of nitrogen, discarded about $1200 \mathrm{cc}$. to the room, completed the maximal expiration to the bag and continued to rebreathe. The third expiration to the bag was limited to about $1200 \mathrm{cc}$., the breath was held in this position of partial expiration for 8 to 10 seconds, and the maximal expiration to the bag was completed. Timed samples were collected from the last portions of the partial expirations before and after holding the breath. The results are shown in Column 6 of Table II and may be compared with those for the same subjects in Column 4 of Table I, since the corresponding experiments were performed on the same day with only 30 minutes to an hour intervening. The average results were not significantly different; as may be seen by inspection of the Tables. The slight average increase of about 4 per cent was in the expected direction for, due to the deeper initial inspiration of nitrogen, the average oxygen consumption in the experiments in which the breath was held was less than 1 per cent of the average basal rate, compared with 9.5 per cent for the rebreathings yielding the results of Table I.

\section{Mixing in the lung-bag system}

No extensive investigation was made of the adequacy of mixing at the time of collection of the first cardiac output sample, since under similar respiratory conditions mixing in the lung-bag system has been found to be complete by other 
workers, Grollman and Marshall (7) in particular. Our data confirm these findings.

Samples of successive inspirations and expirations were taken in control experiments in which the normal subjects rebreathed initial mixtures of 2000 to $3000 \mathrm{cc}$. of nitrogen. Plotting the nitrogen percentages in the samples as a function of the number of respiratory cycles, it was found, as would be expected, that after the $3 \mathrm{~d}$ or 4 th cycle the points representing inspirations and those representing expirations arranged themselves on parallel and slightly converging lines as in Figure 2 , a result similar to that of Lundsgaard and

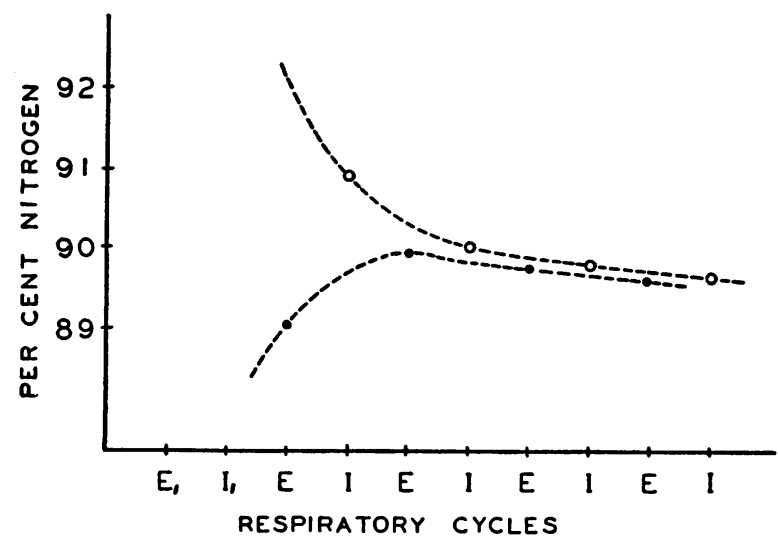

Fig. 2. Nitrogen Percentages during the Period of Mixing

This figure is a representation of several experiments in which normal subjects rebreathed initial mixtures of pure nitrogen. The dots indicate the nitrogen percentages in successive expirations, beginning with $E_{1}$, the initial maximal expiration to the room. The circles are the nitrogen percentages found in samples collected from the last portions of successive inspirations, the initial inspiration, $I_{1}$, being 100 per cent.

Schierbeck (8). (The average nitrogen content was decreasing due to the effect of the blowing off of carbon dioxide.) The nitrogen percentages in the bag samples were slightly above those of the corresponding preceding expirations, since each bag sample was an average of the preceding expiration. This circumstance, found to hold when mixing could be assumed from the results of other workers, was taken as a rough criterion of mixing in the lung-bag system. Additional samples, collected during determinations of cardiac output on 5 out of the 7 clinical subjects studied, satisfied this criterion and demonstrated that there was no serious inadequacy of mixing at the time of collection of the first sample used for the calculation of the cardiac output.

Recirculation and the permissible duration of rebreathing

Discussion of recirculation will be limited to a consideration of significant changes in the oxygen content of the blood returning to the lungs during the course of the rebreathing experiments. In procedures of the nature used here, Donal and Gamble (9) found from the inflections of their carbon dioxide-oxygen tension curves an average recirculation time of 24.5 seconds with ten normal subjects lying at rest. In this investigation a slightly less sensitive but more practical test was employed, in that the values of cardiac output were computed from successive pairs of samples collected during the rebreathing experiments, and significant recirculation was considered to have occurred when the calculated cardiac output decreased more than 10 per cent, as determined from the later sample collections. This does not, of course, distinguish between recirculation and a possible further acceleration in the blood flow during the rebreathing. However, such a distinction is not necessary for present purposes, since a change in the calculated cardiac output from either cause is equally undesirable.

For the 11 normal subjects studied in this investigation the average time of collection of the last sample used for the determination of cardiac output was 23 seconds. With 6 of these subjects a 3d sample was collected from the expiration made two cycles later. Since with only one subject did a significant change ( -15 per cent) in the calculated cardiac output result from a continuation of the rebreathing for two extra cycles, it is believed that the technique prescribed for normal subjects will not, in general, result in errors due to recirculation.

For the 12 experiments with the 7 clinical subjects studied, the average time of collection of the last sample used for the calculation of cardiac output, taken from the 9th expiration to the bag, was 28 seconds. In 7 of the experiments, with 6 subjects, additional samples showed that in only one case could there have been significant recirculation between the 7th and 9th cycles, the cardiac output change being -17 per cent. It is believed, there- 
fore, that the technique prescribed for resting clinical subjects will not extend into the period of recirculation, particularly since the average time required for the procedure could probably be substantially reduced with more experience on the part of the operator.

\section{Miscellaneous assumptions and possibilities of error}

The determination of the oxygen dissociation curves of the blood of each subject is believed to be unnecessary and in this investigation the nomogram of Henderson, et al. (5) has been employed throughout. Comparative calculations made with other nomograms have shown that changes in the cardiac output of a subject may be determined with sufficient accuracy by the use of any standard nomogram. The absolute values of the cardiac output of 9 subjects were systematically decreased by an average of 10 per cent when recomputed from the nomogram of Dill, et al. (10, page 207).

From Equation 2 the values of cardiac output vary inversely as the oxygen capacities of the blood. For normal subjects the use of an assumed blood oxygen capacity of $200 \mathrm{cc}$. per liter has been found, with 9 subjects, to introduce an average error of only +3 per cent into the results. For clinical subjects the oxygen capacities have been determined from hemoglobin estimations.

Since it is impracticable to determine the oxygen saturation of the arterial blood of each subject, the value of 96 per cent has been assumed from the work of Bock et al. (11). A variation of 1 per cent in this assumption will introduce an average error of between 3 and 4 per cent into the calculated cardiac output.

The two determinations of oxygen consumption are performed under identical conditions and are separated by only a short period of time. The work of Grollman (12) and others encourages the belief that this will result in identity of venous oxygen contents. That the venous oxygen content 15 to 25 seconds after beginning to rebreathe is the same as that immediately before the rebreathing begins is supported by the findings of Donal and Gamble (9), and of this investigation, that only occasionally does blood low in oxygen content return to the lungs earlier than about 24 seconds after the start of the rebreathing procedure.
It is believed unnecessary to take account of the absorption of nitrogen from the lungs during the low oxygen rebreathing experiment, since the average increase, although systematic, in the calculated cardiac output resulting from the neglect of this factor can be shown to be less than 1 per cent. If account is taken of the changes in the lung-bag volume during the low oxygen rebreathing experiment, by making use of the altered nitrogen percentage in the second sample as compared with the first, the cardiac outputs of 9 normal subjects have been found to be increased an average of 3 per cent. Although this effect is also systematic, since more carbon dioxide is ordinarily excreted during the period between the sample collections than there is oxygen absorbed, the error is small and is somewhat reduced by the absorption of nitrogen mentoned above. Therefore, for simplicity, this volume change has been neglected in this investigation. ${ }^{8}$

Calculations have shown that no appreciable error is introduced by assuming, in Equation 2, that the entire oxygen consumption during the rebreathing takes place at the average gas tensions found in the samples.

\section{EXPERIMENTAL RESULTS}

The values of cardiac output obtained by the simplified oxygen method were compared with the results secured on the same subjects by means of ethyl iodide and acetylene.

Two determinations of the basal cardiac output of each subject were made, about 20 minutes apart, by the ethyl iodide method of Starr and Gamble (1), using the katharometer as described by Donal, Gamble and Shaw (13). During each determination, duplicate estimations were made of oxygen consumption, of carbon dioxide elimination, and of the oxygen and carbon dioxide tensions of alveolar air.

About 20 minutes later the basal cardiac out-

${ }^{3}$ Correction for this change may be made by merely multiplying the oxygen percentage in the second sample by the ratio of the nitrogen percentage in the first sample to that of the second sample. Thus:

$$
\text { Corrected }\left(\mathrm{O}_{2}\right)_{\mathrm{II}}=\text { Measured }\left(\mathrm{O}_{2}\right)_{\mathrm{II}} \times \frac{\left(\mathrm{N}_{2}\right)_{\mathrm{I}}}{\left(\mathrm{N}_{2}\right)_{\mathrm{II}}},
$$

where the Roman subscripts refer to the respective samples. 
put was again determined by the acetylene method of Grollman (2) in all normal subjects."

After an additional period of 30 minutes rest the oxygen rebreathing procedure was carried out. Still later, supplementary experiments which are described in the preceding section were performed on many of the subjects for the purpose of investigating errors.

In Table I, the results secured by the method described have been compared with those obtained by the ethyl iodide and acetylene procedures. It is concluded from a statistical analysis that there are no significant differences between the averages of the results obtained by means of the three methods.

\section{DISCUSSION}

Reviews of the oxygen and carbon dioxide methods, founded on the principle of Fick, have been given by Grollman (12) and by Richards and Strauss (14). Equilibration of the venous blood with the tensions of oxygen, carbon dioxide, or both gases in the lung-bag system, in the methods such as those of Barcroft, Roughton and Shoji (15), Douglas and Haldane (16) or Burwell and Robinson (17), was a tedious procedure and the difficulties of such an equilibration have been pointed out by Richards and Strauss (14). The equilibration of oxygenated venous blood with the carbon dioxide tension of the gas in the lung-bag system offers obvious advantages, among them that the rate of carbon dioxide transport between the blood and gas is proportional to the difference in the corresponding tensions. Advantage of this fact was taken by Fridericia (18) and by Liljestrand and Lindhard (19).

The "triple extrapolation" method of Redfield, Bock and Meakins (20) represented a simplification of technique in that the tensions of the gases in the mixed venous blood were inferred, by extrapolation, from analyses of mixtures having quite different gas tensions. It has been shown by Donal and Gamble (9), however, that this procedure may lead to erroneous results.

The method here described is much simpler than any of those mentioned above. Various elaborations of it are possible, for instance the

4 Dr. Clarence James Gamble has kindly permitted the presentation of these as yet unpublished acetylene results which formed a portion of a separate investigation. normal arterial oxygen tension might be determined by analysis of blood obtained by arterial puncture. Theoretically, carbon dioxide might be used instead of oxygen, but the many physiological factors influencing the behavior of carbon dioxide in the body make the use of oxygen much to be preferred.

It might be considered desirable, when working with clinical subjects of low vital capacity, to employ two initial breaths of nitrogen before connecting the subject to the final rebreathing bag, in order to reduce the average oxygen tension in the lungs and hence the oxygen consumption during the period between the collection of the timed samples. Or, in order to shorten the time necessary for mixing, other and more complicated rebreathing procedures might be employed. In both cases, however, preliminary experiments have shown that the purely mechanical difficulties of application of such techniques render their value questionable, although they may offer theoretical advantages.

Some question might be raised about the propriety of asking abnormal subjects to inhale nitrogen for about 25 seconds. As is well known there are no subjective sensations from this procedure. Cyanosis has not been observed in our normal subjects. It was seen in one patient at the extreme end of the rebreathing period. Untoward possibilities in this direction should be kept in mind by those planning to use the method in cardiac or pulmonary disease.

Obviously, further experience with the method might indicate the desirability of the use of other values for the average residual air, or other blood nomograms, than those employed in this investigation.

The agreement between the average results obtained by this oxygen method and those secured by the ethyl iodide and acetylene procedures is far from perfect but it is satisfactory enough. In certain individuals the agreement between the results by the three methods is good, in others it is poor. This is in accord with expectations for, when duplicate analyses are made by a single method, some subjects give constant results while others are far more variable. The application of the three different techniques required far more time than that which must separate duplicate estimations. Most subjects cannot be expected to 
maintain a completely constant basal cardiac output over a period of about an hour and a half while undergoing different experiments of an unfamiliar type.

The more elaborate methods of other workers have been evolved to avoid some of the assumptions accepted in our simple procedure. But, in order to avoid these, other assumptions have been accepted and the question must be asked whether anything substantial has been gained by the more elaborate techniques.

\section{SUM MARY}

A simplified oxygen method has been developed by which the cardiac output of either normal or clinical subjects may be estimated from a determination of metabolism and the analysis of the oxygen and carbon dioxide contents of only two samples, collected during a single rebreathing procedure.

The effects of various errors inherent in the assumptions and technique have been investigated. Experimental results have shown that many of these errors are of such small magnitude that they may be neglected. From calculations, and from a consideration of the work of other investigators, it has been concluded that the influence of the remaining apparent errors is likewise relatively unimportant.

The averages of estimations of basal cardiac output by the new procedure have been found to be in good agreement with the averages of determinations made on the same normal and clinical subjects by the ethyl iodide method of Starr and Gamble and by the acetylene method of Grollman. The agreement of estimations by the three methods on individual subjects is not very good, a result to be expected from the known variation of duplicate estimations in many subjects. In seven instances the result of the oxygen method agreed more closely with the average of the ethyl iodide results than with the result of the single estimation by acetylene. In three instances the oxygen result was closer to that obtained by acetylene.

Duplicate estimations by the oxygen method agreed more closely than similar duplicates made by ethyl iodide in four patients.
I make grateful acknowledgment to Dr. Clarence James Gamble and Professor Isaac Starr for their constant encouragement and fruitful suggestions during the course of this investigation, and for their valuable help in the preparation of this manuscript for publication.

\section{BIBLIOGRAPHY}

1. Starr, I., Jr., and Gamble, C. J., An improved method for the determination of cardiac output in man by means of ethyl iodide. Am. J. Physiol., 1928, 87, 450.

2. Grollman, A., A comparison of the triple extrapolation (Fick principle) and the acetylene (foreign gas principle) methods for the determination of the cardiac output of man. Am. J. Physiol., 1930, 93, 116.

3. Gladstone, S. A., The factor of recirculation in acetylene method for determination of cardiac output. Proc. Soc. Exper. Biol. and Med., 1935, 32, 1319.

A modified foreign-gas method for determination of cardiac output in man. Ibid., 1932, 32, 1321.

4. Hurtado, A., and Boller, C., Studies of total pulmonary capacity and its subdivisions. I. Normal, absolute and relative values. J. Clin. Invest., 1933, 12, 793.

5. Henderson, L. J., Bock, A. V., Field, H., Jr., and Stoddard, J. L., Blood as a physicochemical system. II. J. Biol. Chem., 1924, 59, 379.

6. Krogh, A., and Lindhard, J., Measurements of the blood flow through the lungs of man. Skandinav. Arch. f. Physiol., 1912, 27, 100.

7. Grollman, A., and Marshall, E. K., Jr., The time necessary for rebreathing in a lung-bag system to attain homogeneous mixture. Am. J. Physiol., $1928,86,110$.

8. Lundsgaard, C., and Schierbeck, K., Studies on the mixture of air in the lungs with various gases. I. Am. J. Physiol., 1923, 64, 210.

9. Donal, J. S., Jr., and Gamble, C. J., The cardiac output in man. Changes in alveolar oxygen and carbon dioxide tensions during rebreathing and the bearing of these upon the triple extrapolation method of estimating cardiac output. Am. J. Physiol., 1936, 116, 495.

10. Dill, D. B., Bock, A. V., van Caulaert, C., Fölling, A., Hurxthal, L. M., and Henderson, L. J., Blood as a physicochemical system. VII. The composition and respiratory exchanges of human blood during recovery from pernicious anemia. J. Biol. Chem., 1928, 78, 191.

11. Bock, A. V., Dill, D. B., Edwards, H. T., Henderson, L. J., and Talbott, J. H., On the partial pressures of oxygen and carbon dioxide in arterial blood and alveolar air. J. Physiol., 1929, 68, 277.

12. Grollman, A., The Cardiac Output of Man in Health and Disease. C. C. Thomas, Baltimore, 1932. 
13. Donal, J. S., Jr., Gamble, C. J., and Shaw, R., The cardiac output in man. An adaptation of the katharometer for the rapid determination of ethyl iodide in estimations of cardiac output by the ethyl iodide method. A study of the effect of posture upon cardiac output and other circulatory and respiratory measurements. Am. J. Physiol., 1934, 109, 666.

14. Richards, D. W., Jr., and Strauss, M. L., Carbon dioxide and oxygen tensions of the mixed venous blood of man at rest. J. Clin. Invest., 1930, 9, 475.

15. Barcroft, J., Roughton, F. J. W., and Shoji, R., The measurement of the oxygen content of the mixed venous blood, and of the volume of blood circulating per minute. J. Physiol., 1921, 55, 371.

16. Douglas, C. G., and Haldane, J. S., The regulation of the general circulation rate in man. J. Physiol., 1922, 56, 69.

17. Burwell, C. S., and Robinson, G. C., A method for the determination of the amount of oxygen and carbon dioxide in the mixed venous blood of man. J. Clin. Invest., 1924, 1, 47.

18. Fridericia, L. S., Untersuchungen an menschen über Sauerstoff- und Kohlensäurespannung im blut der Pulmonalarterie und über Messung des Minutenvolumens des Herzens. Biochem. Ztschr., 1918, 85, 307.

19. Liljestrand, G., and Lindhard, J., The determination of the circulation rate in man from the arterial and venous $\mathrm{CO}_{2}$ tension and the $\mathrm{CO}_{2}$ output. J. Physiol., 1920, 53, 420.

20. Redfield, A. C., Bock, A. V., and Meakins, J. C., The measurement of the tension of oxygen and carbon dioxide in the blood of the pulmonary artery in man. J. Physiol., 1922, 57, 76.

21. Roth, P., Modifications of apparatus and improved technic adaptable to the Benedict type of respiration apparatus. Boston M. and S. J., 1922, 186, 457. 